\title{
Snare resection after full-thickness resection device malfunction
}

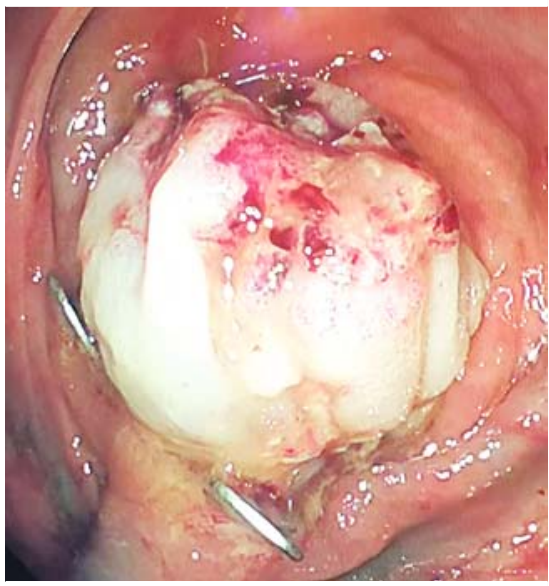

- Fig. 1 Endoscopic view showing the full-thickness resection device (FTRD) clip in place below the lesion.

The full-thickness resection device (FTRD; Ovesco) is approved for the endoscopic resection of invasive lesions in the gastrointestinal tract. It has shown particular promise for incompletely resected colonic polyps and for early invasive lesions in frail elderly patients who are poor surgical candidates [1,2]. The management of technical issues or malfunctions during use of the FTRD is poorly documented in the literature to date. We describe a rare incident of built-in snare breakage during the removal of a transverse colonic lesion in an elderly female patient.

A 15-mm lesion (Paris 0 -IIa +0 -IIc) was identified in the transverse colon. The lesion had NICE type 3 features on narrowband imaging (NBI) indicating probable submucosal involvement. The lesion was first marked and then drawn into the FTRD as per the standard procedure. Once the clip had been deployed, the snare was closed; however, it was immediately noted that the snare wire had fractured during closure. The lesion was subsequently examined carefully to ensure adequate placement of the clip ( $\bullet$ Fig. 1 ) and to assess the feasibility of further intervention. A 15-mm snare was used to resect the lesion above the deployed

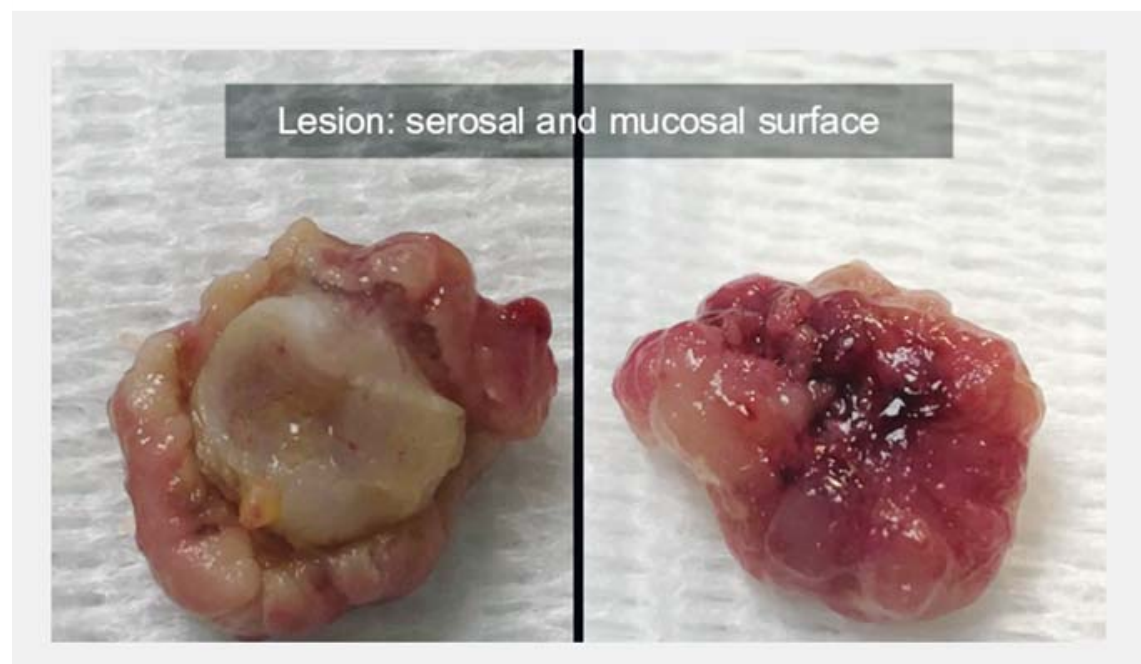

- Fig. 2 Macroscopic appearance of the mucosal and serosal sides of the resected lesion.

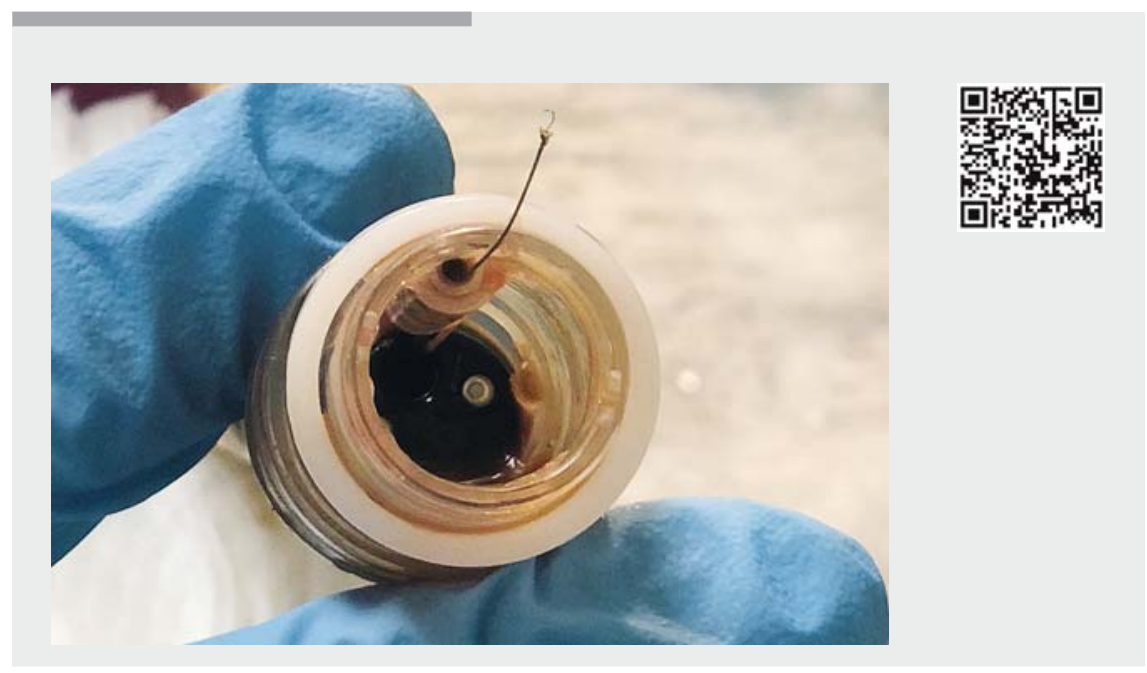

$\checkmark$ Video 1 Resection of a colonic lesion after breakage of a wire in the full-thickness resection device (FTRD) snare.

FTRD clip, using the ERBE system with 150 W of "pure cut" current ( $\vee$ Video 1 ). The lesion was completely resected en bloc ( $\triangleright$ Fig. 2 ). The procedure was performed with the patient under conscious sedation (midazolam and fentanyl), and the patient was able to be discharged home the same day. No immediate or late complications occurred.
Histology of the resected lesion confirmed full-thickness endoscopic resection of a pT1 adenocarcinoma. Further endoscopic assessment 3 months later confirmed that there was no residual lesion.

Endoscopy_UCTN_Code_CPL_1AJ_2AD 
None

The authors

Pardeep Maheshwari, Muhammad Farman, Senthil Kumar Palaniappan, Brendan Doyle, Stephen Patchett, Danny Cheriyan

Department of Gastroenterology, Beaumont Hospital, Dublin, Ireland

Corresponding author

\section{Danny Cheriyan, MD}

Department of Gastroenterology, Beaumont Hospital, Dublin, Ireland

dgcheriyan@gmail.com

\section{References}

[1] Wedi E, Orlandini B, Gromski M et al. Fullthickness resection device for complex colorectal lesions in high-risk patients as a last-resort endoscopic treatment: initial clinical experience and review of the current literature. Clin Endosc 2018; 51: 103 - 108

[2] Aepli P, Criblez D, Baumeler S et al. Endoscopic full thickness resection (EFTR) of colorectal neoplasms with the Full Thickness Resection Device (FTRD): Clinical experience from two tertiary referral centers in Switzerland. United European Gastroenterol J 2018; 6: 463-470

\section{Bibliography}

DOI https://doi.org/10.1055/a-0800-8256

Published online: 14.12.2018

Endoscopy 2019; 51: E45-E46

(c) Georg Thieme Verlag KG

Stuttgart · New York

ISSN 0013-726X

\section{ENDOSCOPY E-VIDEOS}

https://eref.thieme.de/e-videos

口回 Endoscopy E-Videos is a free access online section, reporting 自社: on interesting cases and new techniques in gastroenterological endoscopy. All papers include a high quality video and all contributions are freely accessible online.

This section has its own submission website at https://mc.manuscriptcentral.com/e-videos 